\title{
Discussion on Disaster Education and Prevention Strategies Based on SPSS Analysis - Taking disaster prevention research of Chengdu as an example
}

\author{
Li Yanghui ${ }^{1}$ \\ ${ }^{1}$ Institute for Disaster Management and Reconstruction, Sichuan University, Chengdu, China, 610065
}

\begin{abstract}
Post-disaster prevention strategies and education affect and shape the future development pattern and behavior of disaster prevention and reduction. Chengdu has made great achievements in disaster prevention education after the Wenchuan earthquake. Data from several dimensions has been analyzed through SPSS to explore the reasons for its success. The first dimension is disaster prevention education, including disaster research, disaster educational institution bases and disaster prevention education halls, etc. The second one is legal strategies for disasters, including current disaster-related policies and regulations of Chengdu. The disaster education in Chengdu over the ten years has been reviewed based on the weighted processing of historical data by SPSS. Though achievements have been made, there is room for improvement in the cultivation of a legal cultural concept for disasters and the establishment of a disaster accountability mechanism. Therefore, this paper reviewed the past legal education experience of Chengdu and made targeted suggestions based on the discrete processing analysis of multiple factors of post-disaster education so as to provide more thoughts on future disaster prevention strategies and legal education for disasters.
\end{abstract}

\section{Introduction}

For any country, post-disaster education and prevention strategy construction are effective means to prevent disasters. According to China's specific national conditions, the post-disaster legal cultural education of China must not only follow the core requirements of the rule of law, but also respect China's cultural traditions, current national conditions and citizens' demands. ${ }^{1}$ In this regard, Sichuan Province is undoubtedly a banner on the road of socialist disaster prevention and legal governance. Legal culture is an effective combination of the construction of the legal system and conceptual culture. ${ }^{2}$ Regarding the case of Chengdu, Sichuan Province, we analyzed a large amount of data about disaster prevention policies through SPSS and found that the post-disaster reconstruction of Chengdu after the Wenchuan earthquake was inseparable from the guidance of legal cultural education. The so-called legal culture for disasters is an effective combination of disasters and disaster concepts in disaster prevention, reduction and relief and post-disaster reconstruction, and it is presented by the life style of people in disaster areas and the action of disaster

1 Zhou Yezhong. Thinking about the connotation of "law-based governance in China" [J]. Law and Social Development, 2013, 19(05): 3-5.

2 Liu Zuoxiang. Several theoretical issues of legal culture [J]. Legal Forum, 2012, 27(01): 5-10. prevention, reduction and relief. Some researcher summarized it as the awareness of potential dangers and responses of people during the disaster period. ${ }^{3}$ However, the definition is one-sided. The construction of legal culture for disasters concerns not only the relationship between man and nature, but also that between man and society and between disasters and government functional departments in the event of disasters. The author believes that the legal cultural concept of disasters can be understood as a combination of the construction of the legal system for disasters and disaster culture, and that a legal concept for disasters at national, social and individual levels is finally formed through the adjustment and balance of the relationship between disasters and people, society and government functional departments and the improvement of the legal system for disasters.

\section{A review of Chengdu's 10-year legal education on disaster prevention based on data}

Legal cultural education of disasters refers to the construction of legal cultural awareness and normative systems that can guide the public to adapt to the

$3 \mathrm{Wu}$ Guochun, Tanaka Shigeoka. A preliminary study on the construction of "disaster culture" in Japan - Taking community disaster reduction in Shizuoka, Japan as an example [J]. Disaster Reduction in China, 2006(04):26-27. 
environment resulting in the disaster environment. It is often a legal cultural phenomenon of thinking about or reflecting on the disaster environment after a disaster occurs, which focuses on guiding the public to be able to treat the disaster environment more correctly in the future disaster environment. Specifically, it is mainly manifested in two aspects: first, the educational concept of legal culture for disasters, focusing on the public awareness of disaster behaviors, disaster prevention capabilities, disaster concepts and psychological reactions during disasters; second, legal cultural strategies and norms for disasters, mainly including a series of policies, regulations and systems formulated by government functional departments to improve their legal ability of disaster prevention and reduction.

\subsection{Key points of cultural disaster education projects under SPSS weighted analysis}

In terms of cultural disaster education, we can see that measures have been taken by the municipal government of Chengdu in five aspects according to the weighted analysis on post-disaster education data of Chengdu through SPSS.

1. National Disaster Prevention and Reduction Day. On May 12, 2008, an earthquake of magnitude 8.0 struck Wenchuan, Sichuan, which brought huge losses to the nation. The setup of a "Disaster Prevention and Reduction Day" seemed significant based on the development of the public awareness of disaster prevention, reduction and relief and the improvement of emergency response capabilities after the earthquake. Thirteen commemorative activities with the theme of disaster prevention and reduction have been carried out since its setup in 2009. The setup of the "Disaster Prevention and Reduction Day", especially the publicity and education of legal culture for disasters, has deepened people's understanding of disasters and strengthened their emergency response capabilities for self-rescue and for rescuing others.

2. Chengdu International Intangible Cultural Heritage Festival. The Festival, as an important part of the construction of legal culture for disasters, exerts its unique charm. The third "Chengdu Cultural Heritage Day" event was officially held in June 2008. The Ministry of Culture combined the legal culture of post-disaster reconstruction with the "Intangible Cultural Heritage Festival", creating a new channel for the construction of legal culture. Activities of "Intangible Culture in Communities" have popularized the relationship between disasters and intangible culture to the public and laid a foundation for the inheritance and protection of culture. ${ }^{4}$

3. Construction of a scientific research platform. On June 20, 2008, a "multi-disciplinary" research institute of

477 sub-district-level comprehensive cultural activity centers and 238 township comprehensive cultural stations have been completed and opened so far in Chengdu, realizing full coverage of the cultural front. Cultural centers and libraries in the four hardest-hit areas have basically completed their post-disaster restoration and reconstruction.

Tencent, https://news.qq.com/a/20170809/027268.htm, 2019- disaster prevention and emergency management was established jointly by the Hong Kong Polytechnic University and Sichuan University. It has provided not only feasibility research support and guarantee for postdisaster recovery and reconstruction and physical and psychological relief, but also an important platform for national scientific disaster education in disaster prevention, reduction and relief. In May 2018, an earthquake early warning system was available comprehensively in 60 communities under the cooperation of Gaoxin District, Chengdu and Chengdu Institute of Care-life, ${ }^{5}$ which can give an earthquake early warning within a few seconds or even tens of seconds before an earthquake by community radio, mobile phone, TV and other means based on technology, thus protecting the personal safety of residents effectively.

4. Disaster prevention and reduction education hall. A large number of cultural facilities for disasters represented by the Chengdu Disaster Prevention and Reduction Education Hall publicize and popularize natural disaster knowledge from multiple perspectives and directions by modern high-tech means of presentation, aiming to drive the socialization, popularization and routinization of disaster prevention and reduction education. Most settings in the education hall are based on the combination of sound and light technology, enabling experiencers to have multi-faceted visual and auditory feelings and feel the shock brought by disaster damage and providing a technical platform for the publicity and education of disaster culture.

5. Construction of tourism and cultural industries in disaster areas. The construction of disaster culture concerns not only the restoration of culture and the memorial of pain, but also the development in reconstruction. The tourism industry has been positioned as a leading industry in the National Master Plan for Restoration and Reconstruction after Wenchuan Earthquake issued by the State Council. The tourism industry in disaster areas will play a major role in their reconstruction in the future. ${ }^{6}$ Tourist areas were hit hard after the Wenchuan earthquake. However, the key scenic spots were basically undamaged and the value and attractiveness of their physical resources were not affected. The demonstrative pattern of tourism in disaster areas can, on the one hand, enable the public to learn more about such areas, and on the other hand, promote more economic support for the areas.

\subsection{Strategies and planning of legal construction for disasters}

In terms of policy planning, Chengdu has also implemented three disaster prevention plans and established response strategies at multiple levels ranging

05-01. Why can Chengdu receive an early warning 71 seconds in advance? One article to understand earthquake early warning [EB/OL].

6 Qiu Yunzhi, Cai Shuhua. Research on the reconstruction of ethnic and folk cultural tourism after major natural disasters Taking Wenchuan earthquake as an example [J]. Journal of Sichuan Minzu College, 2013, 22(06): 43-47. 
from the construction of government functions in public affairs to disaster service volunteer teams.

1. $12^{\text {th }}$ Five-Year Plan of Sichuan Province for Disaster Prevention. The Plan connects the national disaster prevention plan and the actual situation of disaster prevention, reduction and relief in Sichuan and is based on the overall situation of disaster prevention and reduction in the province. It mainly addresses the issue of comprehensive disaster prevention and reduction system construction, in which all kinds of disasters in the province have been considered. The construction of government functions has been transformed, and the focus has been on strengthening multi-departmental coordination and disaster prevention and reduction capabilities for joint prevention and control.

2. $13^{\text {th }}$ Five-Year Plan of Chengdu for Disaster Prevention. The Plan has established disaster prevention and reduction targets, striving to build a comprehensive grassroots disaster prevention and relief system and improve public services for disaster reduction within the planning period. It focuses on building a sponge city and strictly mastering the urban disaster prevention standards to achieve a new level of urban natural disaster relief capabilities.

3. Emergency Volunteer Service Management Regulations. An important manifestation of the construction of legal culture for disasters is the autonomy and enthusiasm of social individuals in responding to disasters. Volunteer service teams for disasters are one link of it. In 2008, Sichuan first set up a disaster volunteer service team - Sichuan Provincial Emergency Volunteer Service Corps. In 2014, it was the first to establish a provincial social service center for mass organizations Sichuan Provincial Social Service Center for Mass Organizations. In 2017, the first planning center for disaster prevention, reduction and relief with the participation of social forces in China was established. In 2018, the Emergency Service Center of Sichuan Youth and Social Force Unite Action was established. Moreover, China's first emergency volunteer service standard Emergency Volunteer Service Management Regulations was compiled under the organizational system.

The leapfrog development of the construction of legal culture for disasters is not accidental; instead, it is supported by its objective foundation and subjective motivation. Its objectivity lies in the fact that there are many types of natural disasters in Sichuan Province, with a wide range of distribution and frequent occurrence, such as the Wenchuan earthquake and the Jiuzhaigou earthquake. Once they occur, the losses are difficult to estimate and the disaster risk is extremely severe. In terms of its subjectivity, Chengdu, as the political, economic and cultural center of Sichuan Province, has undoubtedly become a center for the propaganda and education of the legal culture for disasters. The improvement of subjective motivation in the construction of legal culture for disasters has been proved by the construction of its facilities, the development of scientific research platforms, new

7 Zhao Xiaoyan, Feng Jilin, Lu Peng, Jia Zhonghua. On the role of disaster culture in disaster prevention and reduction [J]. Journal of Institute of Disaster Prevention, 2008(02):126-129. development patterns of disaster tourism and active explorations in the reform of the disaster prevention and reduction system.

\section{Experience and enlightenment of Chengdu's disaster education and legal construction based on SPSS weighted analysis}

Culture shapes the disaster prevention and reduction of a country or region through its profound influence on values, norms, beliefs and knowledge according to the discretization and weighted analysis of different factors in disaster education policies of Chengdu over the past ten years. As an important social capital, the legal culture for disasters plays a supplementary role in the improvement of the emergency legal system, the disaster prevention, rescue capabilities of individuals, groups and national functional departments. ${ }^{7}$

\subsection{Establishing three major concepts of disaster prevention education}

In the past, structural disaster reduction was admired to the extent that disaster reduction technology was overstated while the education and propaganda of legal culture for disasters were ignored in the process of enlightenment and education of disaster culture. Therefore, there are a lot of problems even though an earthquake prevention and disaster reduction exploration hall has been set up or a cultural heritage festival has been held in Chengdu. First, the publicity and education of legal culture for disasters often remain at the tool level of simple understanding of disaster-related knowledge and are lacking education on the development of disaster concepts. Second, the inheritance of disaster culture and the promotion of disaster reduction characteristics are ignored. For example, few people can understand the true meaning of "washing riverbed sand deeply and making weirs low" in the publicity of the Dujiang Weir's functions of disaster prevention and reduction in the legal culture for disasters. This is the lack of a cultural view for disasters. Third, active participation in disaster prevention and reduction is lacking. For example, participants are often "forced" to participate in the activity "Disaster Prevention Culture in Communities" jointly carried out by the Institute for Disaster Management and Reconstruction, Sichuan University and communities in Chengdu. One can imagine its effects.

Therefore, the setup of legal concepts for disasters is the first problem to be solved in the establishment of a comprehensive disaster prevention and reduction system. The so-called disaster view is a concept of disasters based on the cognition of the relationship between man and nature and a specific view of life and nature. ${ }^{8}$ Legal cultural concepts for disasters should be developed at

8 Yang Hongliang. Towards culture: path choice of school disaster education $[\mathrm{J}]$. Journal of Chinese Society of Education, 2016(10): 68-71+83. 
three levels, namely the individual, the social and the national level. Individuals and society influence the establishment of a national disaster view which guides the establishment of a more scientific disaster view at the individual and social levels.

1. Development of personal views of disaster culture. Concepts govern behavior, and consciousness determines actions. Disasters are a common enemy of the whole society. Individuals in society must establish personal views of the legal culture for disasters, possess the risk prevention awareness and disaster prevention and reduction capabilities and actively participate in social disaster prevention and reduction. Personal views of the legal culture for disasters should be established in two aspects below:

First, school education on the legal culture for disasters should be enhanced. Popularizing the legal culture for disasters among young people has the most significant effect and can maximize the ability of young people to respond to disasters. ${ }^{9}$ Specifically, we can include disaster prevention education in the nine-year compulsory education, strengthen the guidance and influence of disaster culture and avoid "cramming" education in the secondary school stage, and combine with disaster education bases, disaster tourist attractions, communities and other experiential cultivation. In the university stage, colleges and universities, in particular, should give full play to their main advantages based on the inheritance of disaster culture, including disaster research, disaster cultural propaganda and disaster technology research.

Second, the publicity of disaster culture in communities should be improved, the obstruction of which comes from passive participation and single propaganda mode. What is worth mentioning here is the Japanese community disaster reduction pattern. Shizuoka, Japan, began to promote the "self-service disaster prevention committee" in 1974. It is, in fact, a disaster prevention committee set up by community residents with detailed provisions on member composition, tenure and functions. ${ }^{10}$ Therefore, the pattern can be used for reference for the establishment of personal disaster cultural views of community residents. A "community disaster prevention and reduction committee" can be set up to fully arouse the enthusiasm of community residents, and can also be combined with the "Owner Committee" of residential areas to achieve a multi-functional "Owner Committee".

2. Establishing a social view of legal culture for disasters. To establish a comprehensive disaster prevention and reduction system, the participation of social forces is an extremely important way of implementation. Now, there are more and more activities of seeking public opinions on government-level disaster prevention and reduction regulations or emergency plans, which, however, are not highly involved by the masses and are often left in the cold. Such negativity seems as the

9 Yang Hongliang. Towards culture: path choice of school disaster education $[\mathrm{J}]$. Journal of Chinese Society of Education, 2016(10): 68-71+83.

$10 \mathrm{Wu}$ Guochun, Tanaka Shigeoka. A preliminary study on the abandonment of own rights and interests, but in fact shows that the social view of legal culture for disasters has not really been established. Social subjects should give full play to their unique advantages in all aspects, participate in disaster prevention and reduction and pay attention to various risks around them, forming a new situation of joint participation in disaster prevention and reduction.

Specifically, a disaster cultural museum can be established. The response to natural disasters should not be limited to disaster prevention and immediate response, but should also include the popularization of natural disasters and the construction of natural disaster cultural projects. As Chengdu is the cultural center of the southwest region, the promotion of legal culture for disasters will inevitably play a pivotal role in disaster prevention and reduction in the entire southwest region. However, there are so few disaster exploration halls with public participation in Chengdu, which has become one of the key factors restricting the improvement of disaster prevention, reduction and relief capabilities of the public. To this end, the construction of a disaster museum in Sichuan can be regarded as a cultural engineering carrier concerning the life safety of the masses, which can provide a solid cultural and legal guarantee for the popularization of disaster prevention, reduction and relief culture and for the improvement of the overall ability of government agencies, social organizations and the public to deal with major risks.

3. Establishing a government view of legal culture for disasters. The establishment of a comprehensive disaster prevention system is the foundation of the stable and sustainable development of the nation and an important part of the establishment of a national security view. The Opinions of the Central Committee of the Communist Party of China and the State Council on Promoting the Reform of Disaster Prevention, Reduction and Relief System and Mechanism in 2016 proposed the function transformation from disaster emergency culture to disaster prevention culture construction, that is, adhering to the "prevention-oriented comprehensive disaster prevention and reduction system with prevention and response combination". The way of prevention and of combining prevention and response should be determined in three aspects. First, establishing strict legal policies for disaster prevention. As far as the current disaster legislation is concerned, there are many laws for single disaster types, but the advantage in the number of legislation cannot offset the frequency of disasters. The occurrence of disasters is caused not only by natural factors, but also by human factors. For example, the "forest fire in Liangshan Prefecture, Sichuan Province" originated from man-made fire sources. The "soft effect" of legislation must be transformed into a hard constraint on disaster prevention and control. Second, strengthening input in disaster prevention technology and establishing a concept of disaster prevention and reduction. On the one

construction of "disaster culture" in Japan - Taking community disaster reduction in Shizuoka, Japan as an example [J]. Disaster Reduction in China, 2006(04):26-27. 
hand, the construction of the disaster early warning system should be enhanced. The earthquake early warning system of Chengdu is a good demonstration effect. We can fully exert such positive demonstration effect to strengthen the monitoring of disaster-causing factors. On the other hand, we should strengthen the control of disaster information spreading effect, establish a rapid disaster response mechanism and guide the system of not spreading rumors or believing in rumors about disasters in a timely manner through various channels, including Weibo, self-media and official information channels. Third, building disaster prevention projects, such as the Dujiang Weir, Chengdu, which can on the one hand play its disaster prevention function, and on the other hand strengthen the function of publicizing disaster prevention culture.

\subsection{Establishing a sound legal system for disasters}

The current emergency management system in China is in the period of transition. Disaster prevention education and legal construction are important in the emergency public management system during the period. This also requires changes in government management functions to adapt to actual needs. We carried out a linear analysis of multiple dependent variables leading to disasters based on SPSS, locked those that can be controlled artificially in two directions and proposed corresponding optimization strategies.

1. Improving the adjustment of emergency management functions for disaster prevention, reduction and relief. Changing government functions is a powerful response to sticking to the Chinese road and promoting the Chinese spirit. It is necessary to transform the government from "all-round duty dependence type" to "legal functional type". The so-called "all-round duty dependence type" is actually a functional government based on the planned economy. ${ }^{11}$ The transformation from the duty dependence type must be done towards the path of legal government functions under the background of market economy. It is required to encourage the participation of social forces with the help of market mechanisms under the leadership of the government, thereby enhancing the government's legal ability to prevent and reduce disasters. The current "one plan and three systems" of China's national disaster prevention and reduction system is actually a manifestation of the "allround duty dependence type". The disaster prevention, reduction and relief system seems to fall into a traditional pattern. If we don't take the initiative to reform and transform the function, our emergency response to natural disasters will be powerless with inadequate internal growth conditions once a major and critical emergency occurs. Therefore, we must break the "lock-in effect" and

11 Shi Jianguo. Historical cause and reform direction of allround government functions in China [J]. Journal of China Executive Leadership Academy Jinggangshan, 2015, 8(03): $125-131$.

12 Wang Jianping. " Human disaster-inducing nature" and its make innovation in institutional arrangements. Only in this way can the transformation of government functions be truly realized.

2. Establishing a disaster traceability analysis system and a responsibility mechanism. Disasters are caused by a variety of factors, including both natural and man-made disaster-inducing factors. Some scholars put forward "human disaster-inducing nature" and pointed out that the superimposition of "human" factors caused the expansion of losses incurred from disasters, which further proves the necessity of developing disaster accountability culture after disasters. ${ }^{12}$ Disaster accountability mainly involves top-down and bottom-up accountability pressure. ${ }^{13}$ However, such accountability culture has not actually formed. As the main force of disaster management, government departments must adhere to the following in the development of their responsibility system. First, the division of powers and responsibilities should be clear and the paradox of responsibilities should be eliminated. Responsibilities of government functional departments and their staff should be divided clearly and assigned to specific posts and individuals so as to improve the operating efficiency of the accountability mechanism. Second, political symbols must be prevented in order to achieve disaster accountability. In the construction of disaster accountability culture, the content of accountability should not only target the responsibility itself, but also involve comprehensive reflection on and response to the social system, policies and systems of disaster prevention and reduction with accountability as a starting point, so as to guide the transition of social disaster accountability culture.

\section{Conclusion}

In today's society, post-disaster education has gradually become an important link in disaster risk reduction. According to the analysis of previous disaster prevention data through SPSS, legal cultural elements are actively promoted in disaster plans and their implementation. The role of legal culture for disasters is highly valued in the disaster response stage. While disaster research and understanding are improved based on data analysis, it also allows the public to understand the nature of disaster situations and disaster response behaviors of human fully and correctly and provides an important decision-making basis for the formal disaster response system to respond to disasters effectively. At the same time, the spreading via the public media system reduces the social disorder and loss caused by knowledge deviation. The education on the legal culture for disasters is even more significant at the level of disaster recovery. Post-disaster social education and the formulation of prevention strategies are related to the survival and sustainable development of a country, region and nation.

definition [J]. Journal of Political Science and Law, 2015(06): 311.

13 Tao Peng. Research on disaster management integration from the perspective of vulnerability [J]. Journal of Public Administration, 2013, 6(02): 173-177+182. 


\section{About the author}

Li Yanghui, male, a PhD student in law at the Institute for Disaster Management and Reconstruction, Sichuan University - Hong Kong Polytechnic University; research direction: legal theory and disaster law; E-mail: 1182983364@qq.com;

\section{References}

1. Field, Andy. Discovering Statistics Using Ibm Spss Statistics., 2018. Los Angeles: Sage Publications.

2. Mohan, S. Vijayarani, and Dhayanand Selvaraj. Data Mining Algorithms for Disaster Data Analysis., 2015. Saarbrücken LAP LAMBERT Academic Publishing.

3. Zhou Yezhong. Thinking about the connotation of "law-based governance in China" [J]. Law and Social Development, 2013, 19(05): 3-5.

4. Liu Zuoxiang. Several theoretical issues of legal culture [J]. Legal Forum, 2012, 27(01): 5-10.

5. $\mathrm{Wu}$ Guochun, Tanaka Shigeyoshi. A preliminary study on the construction of "disaster culture" in Japan - Taking community disaster reduction in Shizuoka, Japan as an example [J]. Disaster Reduction in China, 2006(04):26-27.

6. Qiu Yunzhi, Cai Shuhua. Research on the reconstruction of ethnic and folk cultural tourism after major natural disasters - Taking Wenchuan earthquake as an example [J]. Journal of Sichuan Minzu College, 2013, 22(06): 43-47.

7. Zhao Xiaoyan, Feng Jilin, Lu Peng, Jia Zhonghua. On the role of disaster culture in disaster prevention and reduction $[\mathrm{J}]$. Journal of Institute of Disaster Prevention, 2008(02):126-129.

8. Yang Hongliang. Towards culture: path choice of school disaster education $[\mathrm{J}]$. Journal of Chinese Society of Education, 2016(10): 68-71+83.

9. Shi Jianguo. Historical cause and reform direction of all-round government functions in China [J]. Journal of China Executive Leadership Academy Jinggangshan, 2015, 8(03): 125-131.

10. Wang Jianping." Human disaster-inducing nature" and its definition [J]. Journal of Political Science and Law, 2015(06): 3-11.

11. Tao Peng. Research on disaster management integration from the perspective of vulnerability [J]. Journal of Public Administration, 2013, 6(02): 173$177+182$. 